\title{
A PHÝSIS EM SEXTO EMPÍRICO E A CONCEPÇÃO DA NATUREZA COMO GUIA PARA A VIDA ${ }^{1}$
}

\author{
Alice Bitencourt Haddad ${ }^{2}$ \\ Universidade Federal Fluminense (UFF) \\ (iD) https://orcid.org/0000-0002-4690-0878 \\ E-mail: alicecorreio@gmail.com
}

\section{RESUMO:}

Este artigo se divide em duas partes. Na primeira seção, após a introdução, mapeamos as diversas ocorrências de "phýsis" ao longo das Hipotiposes Pirrônicas de Sexto Empírico, dividindo-as em 5 categorias: (1) "natureza" como o real, em posição à "aparência"; (2) o "natural" como aquilo que parece próprio, pertencente a algo ou alguém; (3) a "Natureza", como uma dimensão criadora e regente; (4) o "natural" em oposição ao "antinatural"; (5) a "natureza dos homens". A forma como esses diversos usos aparecem na obra é invariavelmente crítica, como elementos da argumentação contra os dogmáticos, especialmente os estoicos. Na segunda parte do trabalho, entretanto, mostramos como a "phýsis" aparece também de maneira positiva no início das Hipotiposes com a função de guia para a vida, como parte da resposta à célebre objeção da apraxía. Além disso, defendemos a hipótese de que a "natureza", da perspectiva de Sexto, não se opõe nem ultrapassa as convenções e os costumes; pelo contrário, a natureza é o que é reconhecido por todos e é mesmo determinada pelas convenções e pelos costumes.

PALAVRAS-CHAVE: Sexto Empírico; Natureza; Ação.

\section{PHYSIS IN SEXTUS EMPIRICUS AND THE NOTION OF NATURE AS A GUIDE TO LIFE}

\begin{abstract}
:
This paper is divided into two parts. In the first section, after the introduction, we exposed the various occurrences of "physis" throughout Sextus Empiricus" Outlines of Pyrrhonism, dividing them into 5 categories: (1) "nature" as the real, in contrast to "appearance"; (2) the "natural" as that which seems characteristic, peculiar to something or someone; (3) "Nature" as a creative and guiding agent; (4) the "natural" as opposed to "unnatural"; (5) the "nature of men". The way these various uses appear in the work is invariably critical, as elements of argumentation against the dogmatists, especially the Stoics. In the second part of this paper, however, we show how "physis" also appears positively at the beginning of the Outlines with the guiding function for life, as part of the answer to the famous objection of apraxia. In addition, we defend the hypothesis that "nature", from Sextus" point of view, does not oppose nor surpass conventions and customs; on the contrary, nature is what is recognized by all and is even determined by conventions and customs.
\end{abstract}

KEYWORDS: Sextus Empiricus; Nature; Action.

\footnotetext{
${ }^{1}$ Como este trabalho foi apresentado no II Seminário de Pesquisa do PRAGMA, evento em que recebi diversas sugestões e comentários de pesquisadores da área de Filosofia Antiga e Letras Clássicas, aproveito o ensejo para agradecer nominalmente aos professores Auto Lyra Teixeira, Adriano Machado Ribeiro e Olimar Flores Júnior pelas sugestões relativas à tradução; agradeço às professoras Camila Prado de Oliveira e Maria das Graças de Moraes Augusto pelas objeções filosóficas, que nos estimularam a aqui tentar respondê-las, ou, ao menos, a esclarecer melhor a leitura que fazemos de Sexto.

${ }^{2}$ Doutora em Filosofia. Professora da Universidade Federal Fluminense (UFF), Niteroi - RJ, Brasil.
}

HADDAD, Alice Bitencourt. A phýsis em Sexto Empírico e a concepção da natureza como guia para a vida. Griot : Revista de Filosofia, Amargosa - BA, v.19, n.1, p.254-265, fevereiro, 2019. 


\section{Introdução}

Este trabalho se insere no âmbito de um projeto de pesquisa sobre a phýsis em Sexto Empírico. São muitas as motivações para estudá-lo. Em primeiro lugar, é interessante para qualquer amante da Filosofia Antiga, por transmitir um grande conjunto de fragmentos que hoje estariam perdidos não fosse a pertinácia de Sexto em expor passo a passo aquilo que os predecessores entendiam nos mais variados assuntos, dentre os quais, os relativos à Ética, à Física e à Lógica (lembrando que a Lógica incluía o que hoje chamaríamos de Teoria do Conhecimento). Em segundo lugar, o tema da "natureza", da phýsis, é um desses que perpassa todo o pensamento antigo e em contextos variados (político, cosmológico, ético etc.), e Sexto se insere nessa tradição, que é grega, de reconhecer o caráter fundacional da natureza. Ao que parece, os filósofos invariavelmente chegavam a esse inquestionado, ao "natural". Platão, por exemplo, funda sua politeía a partir da acepção de que os érga, os diferentes ofícios praticados na pólis, devam ser conforme a natureza de seus habitantes. Aristóteles, por sua vez, para citar mais um exemplo, na Ética a Nicômaco, flexibilizará a noção de autarquia, de autossuficiência, afirmando que a solidão é incompatível com a natureza política, agregadora, do homem. 0 homem tende, por natureza, a se relacionar. Nessas narrativas, e em muitas outras, a natureza funciona como isso que estamos chamando de princípio fundacional, ele mesmo não questionado nem demonstrado. Do ponto de vista do cético, certamente isso é um problema, pois reside nesses conceitos de "natureza" e de "natural" um campo fértil para o dogmatismo.

Nas Hipotiposes Pirrônicas, texto que elegemos analisar neste primeiro trabalho $^{3}$, a questão da phýsis não será tematizada especificamente em nenhum lugar, porém são frequentes as passagens em que o termo aparece, e em diferentes contextos. Curiosamente, apesar de quase todas as passagens fazerem referência à phýsis de maneira dubitativa e refutativa, em ataque articulado contra as diferentes escolas, há um lugar para a phýsis no ceticismo pirrônico. É no âmbito da ação que Sexto assumirá a natureza como referência. Neste trabalho propomos investigar como Sexto concilia sua crítica às diversas noções dogmáticas de "natureza" com a ideia de que a natureza serve como guia para a vida, conforme o cap. 11 do livro 1 das Hipotiposes. Haveria contradição nessa postura? Num primeiro momento, esclareceremos os diversos usos de phýsis por Sexto Empírico, para, em seguida, apresentar a sua própria maneira de compreender a phýsis no campo da ação. Sexto utiliza o repertório que apresentaremos, em geral, de maneira crítica, mas acaba, assim, nos proporcionando um mapeamento dos diversos sentidos em que a noção de phýsis é utilizada na Filosofia que o precede (embora sem a pretensão de esgotá-los).

\section{Os diversos sentidos de phýsis nas Hipotiposes}

2.1 tê phýsei ou pròs tèn phýsin: é recorrente em Sexto a contraposição entre "aquilo que parece $\mathrm{x}$ " (aquilo que parece bom, doce, redondo, p. ex.) e "aquilo que é x por natureza (tê̂ phýsei)". Como em P. 1.12.27:

\footnotetext{
${ }^{3} \mathrm{O}$ projeto é avançar a pesquisa sobre a phýsis em Sexto de modo a abranger também os Adversus Mathematicos. 
Pois aquele que crê que algo é por natureza belo ou mau se perturbará continuamente; e quando as coisas que lhe parecem belas não estão presentes, julga ser perseguido pelos males por natureza e busca os bens, como acredita; e uma vez que os tenha adquirido, cai em frequentes perturbações e, por temer a mudança, fará tudo para que não perca as coisas que lhe parecem boas. Já aquele que não se define sobre as coisas belas ou boas por natureza nem evita algo nem persegue algo intensamente; por isso, resta sem perturbação ${ }^{4}$.

Nesse contexto, "ser x por natureza" (têe phýsei ou pròs tẹn phýsin) poderia ser entendido por nós como "ser x realmente", "ser x em realidade". Quando da exposição dos dez modos para a suspensão do juízo, essa expressão aparece o tempo todo como o objeto da suspensão. Pelas diferentes impressões (phantasíai) das coisas que subsistem ${ }^{5}$, suspendemos o juízo quanto ao que elas são por natureza. Trata-se da renovação, num outro quadro teórico, do velho par ser-aparência ${ }^{6}$.

2.2 natural como aquilo que parece próprio, pertencente a algo ou alguém: o uso que Sexto faz dessa expressão (pephykótos ou phýsei) parece pouco rigoroso. Ele aponta simplesmente algo que tem uma característica que é reconhecida por todos. Por exemplo: "E uma vez que alguns animais possuem por natureza um brilho nos olhos $[\ldots]$ ". (P. 1.14.45); ou "uma vez que alguns animais são flácidos por natureza e flegmáticos [... $]^{\prime \prime 8}(P .1 .14 .51)$.

Importante, com relação a esses exemplos, que Sexto utiliza a expressão "por natureza" no contexto de um discurso dogmático. Na exposição dos dez modos, as

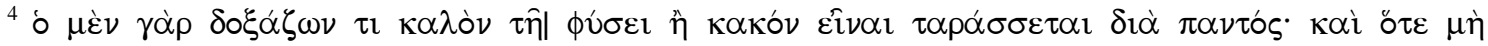

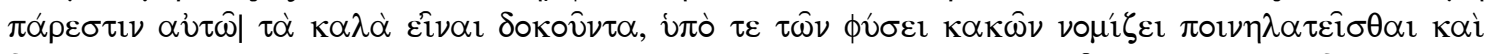

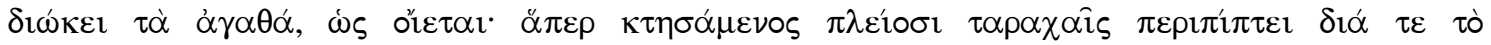

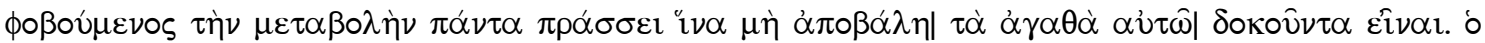

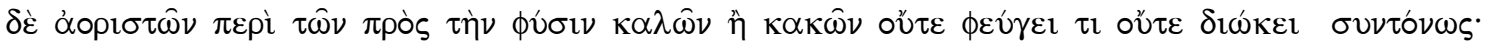

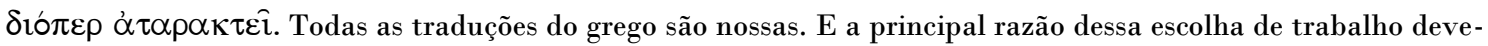
se ao fato de não existir ainda nenhuma tradução das Hipotiposes Pirrônicas para o português. Preferimos, portanto, expor ao leitor o original e a nossa tradução das passagens, para que ele mesmo tenha a possibilidade de fazer o cotejo que julgar necessário. Aproveito também destacar que tradicionalmente se designa o texto das Hipotiposes Pirrônicas com a abreviação P. e o do Adversus Mathematicos com a abreviação M., as quais usaremos daqui por diante. Optamos, ainda, por deixar o grego transliterado no corpo do texto, para imprimir fluidez à leitura. Podemos resumir as regras de transliteração que utilizamos da seguinte maneira: acentuamos todas as palavras da mesma maneira como elas se encontram no original grego; sublinhamos todos os "es" e "os" correspondentes às letras "eta" $\mathrm{e}$ "ômega"; $o$ iota subscrito grafamos com o "i" entre parênteses.

${ }^{5}$ Hypokeímena, que é o termo pelo qual Sexto se refere às coisas das quais adviriam as impressões e que pode ser também traduzido, como faz Bolzani Filho, 1990, p. 42, por "objeto exterior".

6 Já Platão usa phýsis nessa mesma acepção. Veja-se, por exemplo, República, X, 597b-c, em que, no desdobramento da cama em suas três dimensões (a inteligível, a visível que é a cama particular e a visível que é apenas imagem pintada da cama particular), Sócrates chama a cama inteligível de a cama na natureza (en tê̂( $i)$ phýsei) ou a cama natural (phýsei). Em seu comentário à República, Adam chama atenção nessa passagem para o uso que Platão faz da noção de phýsis justamente nesse sentido a que aludimos acima: "With en tệ(i) phýsei cf. infra 597 C, 598 A, Phaed. 103 B and Parm. 132 D [...] Each of these passages brings he phýsis into connexion with the Ideas: cf. also V 476 B, VI 501 B, Crat. 389 B ff. and infra 597 D, E. In the frase en tê (i) phýsei, the expression he phýsis means 'Nature' i.e. rerum natura (cf. R. G. Bury in Cl. Rev. VIII p. 299), but for Plato rerum natura, strictly interpreted, is the Ideal World. Plato's nomenclature is in harmony with the traditional usage of Greek philosophy, for 'in Greek philosophical language, physis always means that which is primary, fundamental, and persistent, as opposed to that which is secondary, derivative, and transient' (Burnet Early Greek Phil. p. 11)."

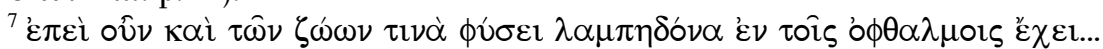

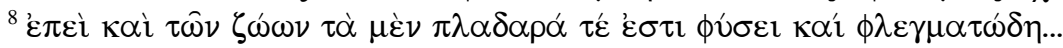


antíteses são formadas a partir de teses dogmáticas, às quais ele não dá adesão. Ele se vale delas apenas para obter a equipolência. Nesse sentido, não se sustenta a atribuição de dogmatismo a Sexto ao se referir ao "natural brilho nos olhos de alguns animais" ou "à flacidez natural de alguns animais". Ele está usando simplesmente a linguagem ordinária e a partir de crenças ordinárias.

Com relação ao uso das expressões à maneira dogmática, cabe salientar que Sexto dedica um capítulo $(P .1 .28)$ a esclarecer essa questão. Ele as utiliza como drogas (phármaka) indicadas como purgantes. Ao serem eliminados os humores do corpo, a droga é expelida junto. Portanto, as expressões e teses usadas nas antíteses, como dissemos, visam à formação de equipolência, sem implicar alguma crença ou afirmação do cético.

2.3 he phýsis como a Natureza: essa concepção aparece pela primeira vez nas Hipotiposes no contexto da tese dogmática da comensurabilidade dos sentidos, em que a Natureza aparece personalizada (por isso, é comum grafar a palavra com "n" maiúsculo), por ser a "autora" da simetria ou proporção entre sentidos e sensíveis: "Mas a Natureza comensurou, dirá alguém, os sentidos de acordo com os sensíveis" (P. 1.14.98).

Essa tese pode ser encontrada tanto em Aristóteles (De Anima 424b20425a13), quanto em vários fragmentos estoicos e visa a responder à dúvida levantada no terceiro modo cético sobre se há (1) mais qualidades sensíveis além daquelas que conhecemos pelos cinco sentidos, se há (2) apenas um sensível que apreendemos de maneira diferenciada pelos cinco sentidos ou se há (3) tantas qualidades sensíveis quanto sentidos. $\mathrm{O}$ cético suspende o juízo com relação às impressões oferecidas pelos diferentes sentidos, porém um estoico como Epiteto, que defende a concepção de uma Natureza divina, regente, racional, conclui não ser possível a arbitrariedade de o homem não apreender a realidade tal qual ela é de fato, defendendo assim a comensurabilidade dos sentidos, isto é, os sentidos apreendem as qualidades sensíveis existentes, nem mais nem menos ${ }^{10}$.

\subsection{Estado natural e antinatural: katà phýsin / parà phýsin ékhein}

O par de opostos katà phýsin e parà phýsin ocorre pela primeira vez nas Hipotiposes no quarto modo da suspensão, o das circunstâncias. $O$ empenho em exemplificar se expressa somente quanto ao estado reconhecido como antinatural. Em estado natural estamos "nós", como aparece nas oposições que ele apresenta: os delirantes e os inspirados pelos deuses parecem ouvir os daímones e percebem odores que nós não sentimos (P. 1.14.101). Em estado natural, segundo o dogmático, está, também, o saudável; enquanto o doente, em estado antinatural ( $P$. 1.14.102-103).

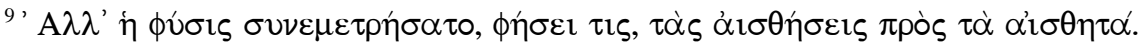

${ }^{10}$ Ver, por exemplo, Discursos 1.6.3-6: “'Se Deus tivesse feito as cores mas não a faculdade de vê-las, qual seria a utilidade disso?' 'Nenhuma.' 'Mas, ao contrário, se tivesse feito a faculdade porém não os seres sujeitos à faculdade da visão, do mesmo modo, qual seria a utilidade disso?' 'Nenhuma'. 'E então? Se ele tivesse feito ambas as coisas mas não tivesse feito a luz?' 'Nem assim haveria uma utilidade.' 'Então, quem juntou isso àquilo

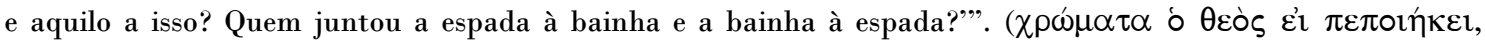

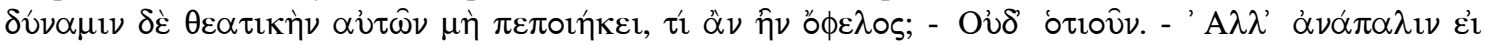

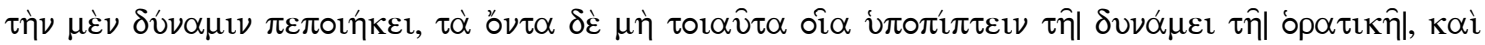

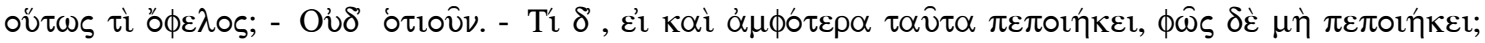

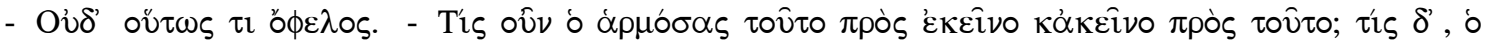

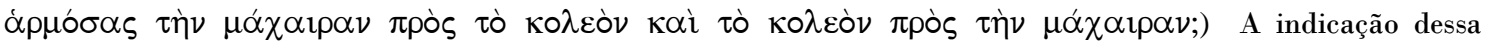
passagem, exata para o contexto, nos veio por ANNAS; BARNES, 1997, p. 75.
} 
Na exposição do quarto modo subjaz a crítica quanto à eleição das melhores condições ou circunstâncias para a apreensão da realidade. Estamos sempre sob alguma condição (dormindo ou acordados; ébrios ou sóbrios; jovens ou velhos etc.), mesmo quando julgamos qual a melhor condição para a apreensão, e por isso não podemos decidir.

Cabem, ainda, duas observações complementares com relação ao par katà phýsin-parà phýsin: primeiro, que ele provavelmente era um tópos nas discussões preexistentes relativas à dúvida quanto ao conhecimento dos sentidos. O próprio Sexto aponta para o uso anterior do par na tese do homem-medida. Ele trata do assunto no cap. 32 , do livro 1 , em que procura diferenciar o ceticismo da doutrina protagórica. Difícil saber se Sexto teve acesso ao Da Verdade, de Protágoras, ou se somente ao Teeteto de Platão. O fato, todavia, é que ele não acena para nada que já não esteja descrito no diálogo, onde se vê o homem parà phýsin como aquele em estado alterado, seja pela loucura, seja pela doença, o que lhe afetaria, segundo a objeção socrática (Teeteto, 157e-158d), a percepção. O mesmo par aparece também no contexto da Nova Academia (p. ex. CÍCERO, Acadêmicas 2.51-52), cujo principal adversário era o estoicismo, uma escola preocupada, como mostra sua teoria da phantasía, em garantir o conhecimento pela percepção. É provável, portanto, que o par estivesse presente, fosse um lugar-comum no debate sobre a verdade e a falsidade das impressões.

A segunda observação importante é com relação ao contexto médico envolvido no par ${ }^{11}$. No quarto modo, para gerar a equipolência, Sexto traz a dogmática teoria médica dos humores, que credita a uma certa mistura de humores a formação de impressões inadequadas. E responde dizendo que todas as pessoas têm alguma mistura de humores que também interferem na produção das impressões. Se todos temos mistura de humores interferindo na produção de impressões, inclusive quando precisamos decidir sobre qual a mistura adequada ou natural para a produção de impressões, suspende-se o juízo. $O$ contexto médico retorna no capítulo 34, quando Sexto se dedica a distinguir o ceticismo da medicina empírica, apontando, em sua exposição, a escola metódica como a mais próxima do ceticismo. Não entremos nesse assunto, que importa pouco para o nosso tema, mas atentemonos para o fato de que o par katà phýsin-parà phýsin retorna ali na descrição dos procedimentos da escola metódica, que parte das afecções aparentes (tôn phainoménon pathôn), tanto as naturais quanto as antinaturais (tộn te katà phýsin kai tôn parà phýsin), para fins de registro e descoberta de tratamentos (cf. P. 1.34.239240). A abordagem de Sexto aqui chama a atenção pelo uso acrítico das expressões, embora dê a entender que ambos os tipos de afecção, tanto as chamadas naturais quanto as chamadas antinaturais, têm igual relevo na escola metódica. Mas, de todo modo, destaca-se aqui e em outros lugares da obra esse uso pouco rigoroso das expressões quando o contexto é o da linguagem ordinária, quando o que está em jogo

\footnotetext{
11 O tema é crucial na distinção entre as escolas médicas no período de Sexto, segundo FREDE, 1987, p. 245. De um lado, os racionalistas, com uma teoria da constituição corporal baseada na concepção de estados naturais e antinaturais, e em busca de suas causas (sobre ela incide a crítica de Sexto no quarto modo, que apresento em resumo em seguida no texto). De outro lado, os empiristas, que, diante de muitas e diferentes teorias racionalistas, não viram utilidade em seguir uma, assumindo o acúmulo de experiências diretas e indiretas como base para os procedimentos da escola. Sobre o desenvolvimento da escola empírica e sua transformação pelo contato com o pirronismo, ver o mesmo FREDE, 1987, p. 251-257.
}

HADDAD, Alice Bitencourt. A phýsis em Sexto Empírico e a concepção da natureza como guia para a vida. Griot : Revista de Filosofia, Amargosa - BA, v.19, n.1, p.254-265, fevereiro, 2019. 
não é a proposição de verdades sobre o mundo. Para comunicar, o cético precisa se valer dos significados reconhecidos pelo senso comum, ainda que em outros momentos ele coloque em questão justamente os sentidos reconhecidos pelo senso comum. No caso específico do par parà phýsin-katà phýsin, todavia, as expressões, embora pertencentes à linguagem ordinária (assim como usamos hoje as noções de "normal" e "anormal"), estão inseridas também no contexto das teorias médicas, que supostamente justificariam, racionalmente, seus usos na fala corrente ${ }^{12}$.

\subsection{A natureza dos homens (he anthrópon phýsis)}

A noção de natureza humana é a única mais desenvolvida positivamente por Sexto, quando da apresentação da conduta cética na vida (que abordaremos na segunda parte do trabalho). Por enquanto, ainda partindo da crítica aos dogmáticos, nos limitaremos a comentar a visão que ele apresenta da noção de "natureza humana" no estoicismo. Assim como na crítica à noção de Natureza regente, Sexto considera a visão estoica da natureza humana uma extrapolação. Ao considerarem que há uma arte da vida (he perì tòn bíon tékhne, $P$. 3.23.244), que a prudência (phrónesis) é apreensível e que o sábio possuidor da arte da vida é alguém cujas ações são consistentes, contínuas, os estoicos estão falando demais (hyperphthéngousin), ou superestimando a natureza humana; estão mais para rezadores ou suplicantes (eukhómenoi) do que para contadores de verdades (talethê légontes) ${ }^{13}$.

A crítica de Sexto não segue irrestrita contra uma noção de natureza humana, mas contra noções que deixam de lado o evidente, o que é reconhecido por todos. Veremos agora, na segunda parte do trabalho, como a natureza dos homens é pensada por ele, e como a própria noção de "natural" apresenta limites rígidos com vistas à precaução contra o dogmatismo.

\section{A natureza como guia para a vida}

Como dissemos anteriormente, a despeito de a noção de phýsis aparecer nas Hipotiposes muitas vezes de maneira crítica, outras dentro de um contexto dogmático para a formação de equipolências - em outras palavras, a despeito de toda a precaução com essa noção que serve de base para muitas teorias e argumentos dogmáticos -, encontramos logo no início da obra um uso positivo dela, como critério de ação. O tema surge no capítulo 11 do livro 1, intitulado "Do critério do

\footnotetext{
12 Valerá a pena em outra oportunidade retomar este assunto, que nos parece frutífero na investigação do uso dogmático da noção de "natural" e que se faz presente ainda hoje nos discursos que apontam a diferença e dizem "isso é contra a natureza". Uma passagem que ilustra bem o par katà phýsin-parà phýsin seria a seguinte: "E uma vez que os saudáveis se encontram em estado natural segundo os saudáveis, e em estado antinatural segundo os doentes, do mesmo modo os doentes se encontram em estado antinatural segundo os saudáveis e em estado natural segundo os doentes; de modo que devemos confiar que aqueles relativamente se encontram em estado

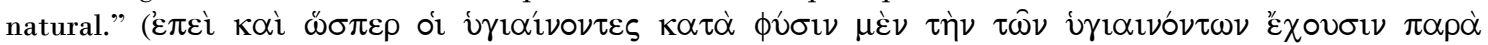

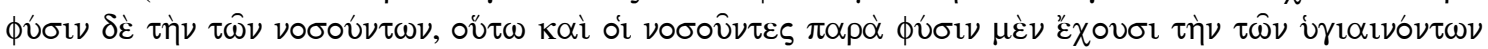

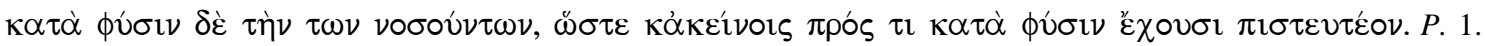
14.103).

13 " $[. .$.$] a afirmação de que apreendemos aquele que possui uma arte da vida pela regularidade de suas ações vem$ daqueles que se excedem ao falar da natureza humana, estando mais para rezadores do que para contadores de

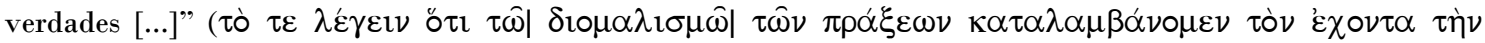

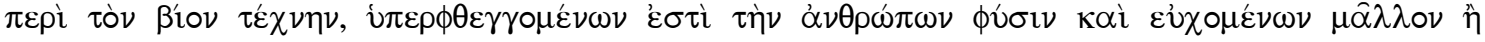
$\tau \dot{\alpha} \lambda \eta \theta \hat{\eta} \lambda \varepsilon \gamma \delta \delta \tau \omega \nu \cdot[.$.$] P. 3.23.244). Para uma análise detalhada da crítica de Sexto aos estoicos, no que diz$ respeito à arte da vida, e as respostas que poderiam ser dadas às suas objeções, ver SELLARS, 2009, p. 88-103.
}

HADDAD, Alice Bitencourt. A phýsis em Sexto Empírico e a concepção da natureza como guia para a vida. Griot : Revista de Filosofia, Amargosa - BA, v.19, n.1, p.254-265, fevereiro, 2019. 
ceticismo". Lá, Sexto afirma que o critério pode ser compreendido de duas formas: como "aquele que determina a crença numa realidade ou numa irrealidade" (aquilo que em outros momentos, especialmente em Contra os lógicos, ele chamará de critério de verdade, que diz respeito ao conhecimento); e o outro seria o critério de ação (tò toû prássein), a partir do qual realizamos certas ações ou as evitamos em nossa vida. Se a epokhé é recorrente no primeiro caso, por sermos juízes parciais que só têm acesso às próprias impressões, e não à realidade; no segundo caso o mesmo não se dá. Não é possível suspender a atividade da vida. E isso não só porque a indecisão gera consequências no mundo real (a omissão é ela mesma uma decisão que produz fatos), mas porque há algo de constrangedor nas motivações para a ação ${ }^{14}$. Sexto dirá que o critério de ação é o fenômeno, e que ele depende de afecção involuntária (abouléto páthei). Isso fica mais claro na sequência do argumento, quando Sexto desdobra a conduta de vida em quatro aspectos: (a) orientação da natureza (hyphégẹsis phýseoss); (b) constrangimento das afecções (anánk pathônn); (c) tradição das leis e dos costumes (parádosis nómonn te kai ethônn) e (d) no ensino das artes (didaskalía tekhnộn).

O constrangimento das afecções ele exemplifica com a fome e a sede. Ao sentirmos fome, buscamos comer; ao sentirmos sede, buscamos beber.

A tradição das leis e dos costumes é a orientação que recebemos culturalmente sobre o bem e o mal, o belo e o feio, sobre o que deve ou não ser feito. Sexto dedica muitas páginas a esse item tanto na discussão do décimo modo da suspensão, dedicado aos assuntos relativos à ética, quanto em sua obra Contra os eticistas. Vê-se dele um intenso empenho em mostrar como não sabemos se há e o que seria o bem por natureza ou o mal por natureza, e ele o faz a partir das antíteses, contrapondo costumes diferentes, leis diferentes, costumes a leis etc. Não podendo decidir entre as diversas concepções de bem, suspendemos o juízo com relação ao bem por natureza (ou, como dizemos habitualmente, o bem em si). Suspendemos o juízo, mas não podemos suspender a ação. E, nesse sentido, o cético é, antes de tudo, um prudente ${ }^{15}$, ou, se quisermos usar uma palavra um pouco mais dura, um conservador. Ele nada afirma sobre a existência de deuses, mas se a tradição entende ser bom ser piedoso, o cético agirá como um (cf. $P$. 1.11.24). Ele se conduzirá de maneira a não ser reprovado por seus concidadãos, evitando as ações e posturas escandalosas que ele sabe, bom frisar, que não são más nem vergonhosas em si mesmas, mas porque os costumes e as leis lhe ordenam. Julia Annas (2007, p. 24-25) atribui certa passividade ao pirrônico, que respeita as instituições de seu país, ou os costumes de seu povo mesmo sem considerá-los justos em si, ou dignos de obediência por si. É como se o cético se destacasse, descolasse, de seu próprio "interior", agindo, estranhamente,

${ }^{14}$ Hume, em uma crítica aos pirrônicos, entendeu perfeitamente aquilo que o próprio Sexto afirma sobre a impossibilidade da apraxía: "Quando [o pirrônico] acordar do seu sonho, será o primeiro a tomar parte na risada geral contra a posição que tomou e a confessar que todas as suas objeções não passam de simples passatempo e a outra coisa não podem tender senão a mostrar a estranha condição humana, obrigada a agir, a raciocinar e a crer, embora seja incapaz, por mais longe que leve as suas pesquisas, de alcançar a certeza sobre os fundamentos dessas operações ou de afastar as objeções que se levantem contra eles" (Investigação sobre o Entendimento Humano 12.2.128, grifos nossos).

15 Será que não podemos entender essa "prudência" em sentido largo como aquilo que Sexto, em Contra os Eticistas (M. 11.165), chama de aphilósophos téresis?: "Ao dizerem isso, não compreendem que o cético não vive segundo o discurso filosófico, porém pode escolher e evitar coisas conforme a observância não-filosófica". $\tau \alpha \tilde{\tau} \tau \alpha$

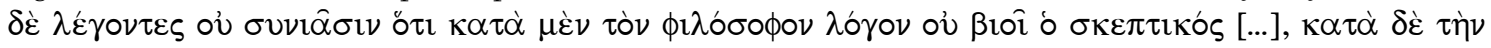

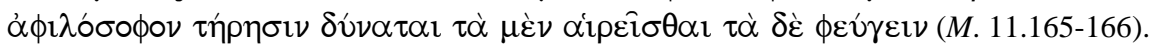

HADDAD, Alice Bitencourt. A phýsis em Sexto Empírico e a concepção da natureza como guia para a vida. Griot : Revista de Filosofia, Amargosa - BA, v.19, n.1, p.254-265, fevereiro, 2019. 
sem partir de crenças. Essa que seria a vida "adoxástica". Uma outra forma de entender a atitude do cético é pensá-lo como alguém que não recusa o mundo que lhe aparece. Ele vive numa região com leis e costumes, as reconhece; porém, também ciente das leis e costumes de outros povos e culturas, percebe-se juiz imparcial na reflexão sobre essas práticas que lhe são estranhas. Suspende o juízo sobre o "melhor em si”", mas isso não significa que uma escolha não lhe apareça como a melhor. Não precisamos ter uma teoria ética, stricto sensu, para nos sentirmos impelidos a agir de uma determinada maneira ${ }^{16}$. Algo nos aparece como o melhor a ser feito e o fazemos ${ }^{17}$.

O ensino das artes também é acatado sem questionamentos. A prática dos ofícios que têm um efeito útil na vida das pessoas, da cidade, não é questionado. $O$ ceticismo não se estende aos conhecimentos produtivos, à construção de casas, por exemplo, ou à agricultura ${ }^{18}$. $\mathrm{O}$ alvo do pirronismo são, fundamentalmente, as teorias filosóficas, que propõem sistemas explicativos que partem do não-evidente.

Resta explicar o aspecto da orientação da natureza na condução da vida. Como é possível a Sexto falar de "natureza" sem cair ele mesmo num dogmatismo? Cremos que a chave está em pensar nos limites discursivos do cético. Se o cético é aquele que se limita a descrever o que lhe aparece, sem avançar na direção do que não é evidente, sua leitura da natureza vai ser, paradoxalmente, uma descrição do que aparece como natural. Mas qual a noção de natural que resta a Sexto? Selecionamos duas passagens nas Hipotiposes que podem contribuir para uma resposta. $\mathrm{O}$ livro III, cap. 21 , sobre se há algo por natureza bom, mau ou indiferente, Sexto inicia assim: "O fogo que aquece por natureza aparece a todos como aquecedor, e a neve que resfria por natureza aparece a todos como resfriadora ${ }^{19}[\ldots]$ (P. 3.21.179). Ainda nesse livro, uma passagem nessa mesma linha chama a atenção. Após descrever as diferentes dietas e proibições alimentares de acordo com as diferentes religiões dos diferentes povos, Sexto conclui: "E, se as < práticas> rituais e

\footnotetext{
16 Para um artigo apenas sobre esse tema, ver SPINELLI, 2012, que defende a ideia de que Sexto não abandona completamente a vida teórica, mas que ele a restringe aos phainómena, ao que aparece. "O que Sexto está oferecendo é um modelo alternativo de racionalidade, uma que é fundada empiricamente" (p. 116). Se há teoria baseando a ação em Sexto, ela não é fundada em não-evidentes, ou no conhecimento da realidade, mas da “interação empírica com aqueles costumes e hábitos que são formatados pelas normas tradicionais e leis do país de origem. Em termos de escolha prática e de comportamento cotidiano, o cético, então, se apoia num sistema complexo e articulado de pontos de referência já dados" (p. 112). Antes de Spinelli, FREDE, 1987, já defendia, em linhas gerais, a mesma ideia, embora seu foco, na explicitação do empirismo presente no ceticismo, seja a teoria médica.

${ }^{17}$ Em M. 11.166, Sexto descreve o célebre exemplo do homem ameaçado por um tirano, que lhe exige agir contra a lei. O interessante da passagem é o uso que o filósofo faz do termo prólepsis ("pré-concepção", ou "noção prévia"). É por meio dessas noções prévias (ou seja, desses pensamentos preexistentes em nós) relativas às leis e aos costumes da pátria (katà toùs patríous nómous kaì tà éthe ) que podemos escolher ou evitar certas ações. Portanto, não é o caso que, por suspender o juízo com relação à natureza do bem e do mal, algo não apareça, não apareça como conteúdo mental (prólépsis), como o melhor ou o que deva ser feito.

${ }^{18}$ Em Contra os gramáticos (M. 1.50-51), Sexto afirma que o fim de toda arte (tékhnê) está em ser útil (eúkhrẹston) à vida. Algumas, impedindo danos; outras, buscando benefícios. Sobre as tékhnai não reprovadas por Sexto, fundadas na observação do frequente e por não almejarem o universal e o necessário, ver BOLZANI FILHO, 1990, p. 47-49.

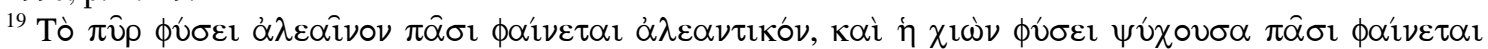

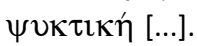


de proibições [alimentares] existissem por natureza, elas seriam reconhecidas por todos de modo semelhante ${ }^{20 "}(P .3 .24 .226)$.

O que essas e outras passagens indicam é que Sexto está tomando o "natural" como aquilo que é reconhecido por todos. Um cético não afirma sobre a realidade do calor do fogo, mas percebe regularmente - algo que é compartilhado por todos - que na presença do fogo as coisas esquentam. Ele não afirma sobre a realidade resfriadora da neve, mas percebe, e em comum com todos, frequentemente que, na presença da neve, as coisas resfriam ${ }^{21}$. Ele assume aquela segunda noção de "natural" que elencamos, "aquilo que é próprio ou pertence a algo ou alguém", mas limita essa noção ao parecer de "todos" 22 . Isso soa paradoxal porque submete a natureza ao aparecer, ao reconhecimento. Entretanto, ao ser bem específico, limitando o natural ao parecer de todos, a noção de natureza será bem restrita. Por isso que os estoicos falam demais ao proporem uma arte da vida a ser buscada pelo homem. Isso é superestimar a natureza humana, diz Sexto. O que no homem é reconhecido por todos? Desdobrando a questão em perguntas anteriores: primeiro, o que em mim é reconhecido por mim? Em seguida, o que nos demais homens é reconhecido por mim? E, por último, o que é reconhecido por mim e pelos demais homens nos homens e em comum? Muito pouco. Sexto dirá simplesmente: somos percipientes (aisthetikoí) e pensantes (noêtikoí). Vejam que a orientação da natureza não pode ser confundida com uma regra de vida em sentido prescritivo. Não é possível viver sem sentir nem pensar.

No cap. 33, dedicado a distinguir os pirrônicos dos acadêmicos, Sexto descreverá a conduta de vida cética de uma maneira um pouco diferente, afirmando que "nós [pirrônicos] vivemos de maneira adoxástica, seguindo as leis, os costumes e as afecções naturais" ( $P$. 1.33.231). Reúne, assim, numa única expressão o constrangimento das afecções à orientação da natureza. Como percipientes e pensantes somos afetados involuntariamente pelos mais diversos fenômenos, tanto sensoriais quanto inteligíveis: não conseguimos evitar sensações e pensamentos. É importante frisar isso para mostrar que a suspensão não é dessa ordem. Ela pode vir num passo posterior, se passarmos a afirmar a partir das sensações e pensamentos. Se da descrição daquilo que nos aparece saltarmos para a descrição do que ocorre de fato, em realidade. Reparem que isso que é descrito como o natural em nós não será ampliado para uma tese sobre o homem. Pelo contrário, Sexto dedicará também um capítulo (5 do livro 2) para questionar essa noção.

Para concluir, como explicar em algumas poucas palavras isso que compreendemos como a orientação da natureza? Enquanto escrevo ${ }^{23}$ sinto cansaço,

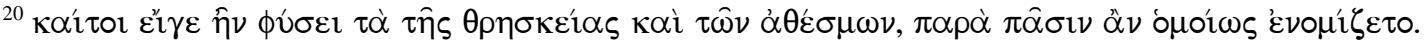

${ }^{21}$ Assumir a sequência de fenômenos "fogo-aquecimento" ou "neve-resfriamento" não leva a um dogmatismo se o que fazemos é simplesmente descrever uma experiência frequente e compartilhada. Dogmatismo seria afirmar o aquecimento como uma propriedade essencial do fogo, por exemplo; passar a descrever a natureza invisível do fogo, suas propriedades ocultas, tomar o aquecimento como um efeito da natureza do fogo. O que o ceticismo faz é descrever a constatação "na presença do fogo, aquecimento". O fogo, portanto, aparece como aquecedor. Essa aparência frequente e observada por todos é dita a "natureza" do fogo. Para quem quiser se aprofundar nisso que seria o conhecimento empírico no pirronismo, recomenda-se o já citado BOLZANI FILHO, 1990.

${ }^{22}$ Sobre o "aparecer a todos" e a relevância da experiência de mundo intersubjetiva no pirronismo, recomenda-se "O phainómenon e a vida comum", em PEREIRA, 2007, p. 303-306.

${ }^{23}$ Nesse trecho usamos a primeira pessoa do singular para enfatizar a singularidade da experiência daquele que se volta para si mesmo e passa a descrever o que sente e pensa.
}

HADDAD, Alice Bitencourt. A phýsis em Sexto Empírico e a concepção da natureza como guia para a vida. Griot : Revista de Filosofia, Amargosa - BA, v.19, n.1, p.254-265, fevereiro, 2019. 
tenho ideias, tenho vontade de tomar um café, a orelha coça, me vem à memória que daqui a pouco preciso sair pra buscar os filhos na escola. Temos experiências relativas ao pensamento e à percepção que não recusamos e não podemos recusar. No presente momento tenho também recordações, de modo que as experiências passadas (ou versões das experiências passadas) também constituem meus pensamentos e sentimentos e de alguma maneira também determinam a minha maneira de me relacionar com as coisas e as pessoas. E seguimos vivendo independente de qualquer sistema explicativo que dê conta do cansaço, do surgimento ou da conexão de ideias, e da vontade de coçar a orelha, por exemplo. Não precisamos entender como opera o desejo para termos um desejo e buscar satisfazê-lo. Não precisamos de uma teoria etiológica para associarmos um fenômeno a outro e termos a expectativa (e somente isso) de que algo irá acontecer se dadas condições se apresentarem ${ }^{24}$. É disso, parece, que o cético está falando ${ }^{25}$. Que não faz sentido exigir verdades sobre o mundo para se viver. Isso não é exigido do homem comum e, no entanto, ele vive ${ }^{26}$ reconhecendo tanto as imposições da natureza, quanto as imposições das leis e dos costumes. E é só isso que podemos fazer, descrever como as coisas se dão. Qualquer tentativa de valorar, de hierarquizar esses aspectos, seria já uma extrapolação, seria já dogmatizar.

Veja-se, todavia, que essa vida conforme à natureza curiosamente está subordinada às convenções. Por dois motivos: (1) como vimos anteriormente nas passagens elencadas ( $P$. 3.21 .179 e 3.24 .226$)$, a própria noção de natureza se compreende como aquilo que é reconhecido por todos. Sexto parece (é a hipótese que procuramos defender), portanto, não compreender "natureza" como aquilo que está para além da percepção, como o "essencial" em oposição ao aparente. Pelo contrário, compreende o "natural" como o "reconhecidamente comum a todos". (2) Ao definir o natural em nós, homens, como a capacidade de sentir e pensar, Sexto ilustrou o homem como uma espécie de receptáculo de dados, tanto de ordem sensorial, quanto de ordem inteligível, e que tende a conectá-los a partir de sua memória. Por exemplo, quando vejo agora a árvore no meu quintal, penso que o nome do fruto que ela dá é romã, e que é comum sua utilização para o combate à dor de garganta; me lembrei de que a ganhei do meu cunhado, quando ainda estava casado com a minha irmã; quando ponho as sementes com a polpa na boca, sinto gosto de chiclete. E podemos montar outros tantos relatos descritivos a partir da experiência com todos os objetos à nossa volta (a árvore de Natal, o porta-retrato com um membro da família, o computador à frente etc.), que nos aparecem em conjunto com uma enorme gama de informações (científicas, afetivas, sensoriais, da ordem do costume etc.) aprendidas ao longo do tempo. Como pensantes e percipientes, temos esse crescente acervo de

\footnotetext{
24 Não conseguimos evitar certo senso de sequência (akolouthía), por meio do qual o homem "se recorda de quais coisas ele observou com quais, e de quais antes de quais, e de quais depois de quais, e, a partir de sua experiência com coisas anteriores, ele revive as demais." $M .8 .288$.

25 PEREIRA, 2007, p. 305, traduz de maneira mais clara essa ideia nas seguintes palavras: "Porque é preciso reconhecer que antes, durante e depois do filosofar, estamos sempre experienciando nossa vida. Nossa experiência de mundo é a experiência de nossa vida cotidiana. Uma experiência que os humanos todos compartilham. Seguir os fenômenos é seguir a vida." (grifos do autor).

${ }^{26}$ Em capítulo sobre os sofismas (P. 2.244), diz Sexto: “Assim, de fato, certo filósofo, quando perguntado sobre o argumento do movimento [supõe-se que o de Zenão], calado pôs-se a caminhar; e as pessoas que seguem a vida viajam por terra e mar, constroem navios e casas e engravidam despreocupadas quanto aos argumentos do movimento e da geração.".
}

HADDAD, Alice Bitencourt. A phýsis em Sexto Empírico e a concepção da natureza como guia para a vida. Griot : Revista de Filosofia, Amargosa - BA, v.19, n.1, p.254-265, fevereiro, 2019. 
experiências ${ }^{27}$ que não são particulares apenas. Estamos imersos numa intrincada rede de dados sensoriais e inteligíveis, como dissemos acima, compartilhados, em larga medida convencionados, de modo que nossa própria natureza pensante e percipiente está a ela subordinada. Isso sem entrar no delicado tema da linguagem que herdamos, em que estamos inseridos, por meio da qual pensamos e nos expressamos, ela mesma convencional ${ }^{28}$ e determinante em nossa experiência de mundo ${ }^{29}$.

É possível ver nisso algo de negativo, como uma espécie de declaração da nossa limitação, da diminuição do nosso horizonte criativo e de ação; mas é justamente essa visão que nos previne de tomar o parcial, o relativo, como o todo, ou o real. Ao nos sabermos situados e determinados pela nossa educação, história, território, cultura, enxergamos o outro como um igual em condições (igualmente determinado por sua educação, história, território, cultura). Isso não é pouco, em especial contra certo tipo de dogmatismo, aquele que pode ser expresso da seguinte maneira: "aquilo que me parece o melhor é o melhor absolutamente. Aquilo que me parece ruim é ruim absolutamente." O ceticismo é um remédio contra esse pensamento que chamaríamos de totalizante, que toma o particular como universal $^{30}$, ou o fenômeno privado como o real. Resvalando para o campo da ação, especialmente da política, o homem do discurso totalizante se vê legitimado, pela verdade que acredita ter, a impor o "melhor" a todos, impedindo a pluralidade de perspectivas e o contraditório. E como a noção de phýsis é bastante útil ao propósito totalizante, a atitude cética nos parece uma saída para o problema. Diríamos mais, que é a noção de parà phýsin, de "antinatural", de "anormal", que contamina o discurso e as ações totalizantes. $\mathrm{O}$ que pode ser mais desviante, anti-humano do que ser ou agir contra a própria natureza? É sobre essa imputação - "isso é contra a natureza" - que o discurso totalizante se apoia. E o que o ceticismo propõe é justamente uma espécie de cura para essa doença que ele nomeia como "a pretensão e a precipitação", como diz Sexto Empírico no último capítulo das Hipotiposes. O pirrônico é um philánthropos (P. 3.32.280), um amante da humanidade. Ele não se alheia, como pode parecer, e viverá como um médico cujos remédios são os diferentes argumentos, modos de persuasão, variando de interlocutor a interlocutor o grau de dificuldade, a fim não de trazê-lo para outra verdade, a "verdade dele, cético", mas para deixá-lo sem verdade nenhuma, em dúvida, em estado de suspensão.

\footnotetext{
27 Sobre a importância das experiências passadas para o cético, ver P. 2.102, PEREIRA, 2007, p. 307 e BOLZANI FILHO, 1990, que trata da dimensão positiva da empiria na condução da vida.

${ }^{28}$ Cf. P. 2.214, sobre a convencionalidade da linguagem.

29 Sobre nossa relação com o Mundo, condicionada pela cultura e pela civilização, em seus modos também de pensar e dizer, ver PEREIRA, 2007, em especial, p. 45-53.

30 Uma objeção nos vem à mente quando estudamos o assunto: será que a visão de respeito à diversidade de culturas não levaria a um relativismo danoso, na medida em que não deveríamos estranhar e desejar eliminar os costumes estrangeiros que nos parecem horríveis (como a opressão de mulheres ou o assassinato de dissidentes por um governo)? Uma possibilidade de saída para a questão, que aqui não teríamos condições ainda de explorar, é pensar que além de nossa própria comunidade local, que decide suas leis e costumes (nossa associação de moradores, nossa cidade, nosso estado etc.), vivemos em uma grande comunidade global, que também pode decidir suas regras de convivência. $O$ importante nos parece entender que qualquer tentativa de afirmar valores comuns é firmada por convenção, é resultado de experiências históricas, elas mesmas determinadas pelas forças em embate, e não por uma ideia de um bem ou justiça a priori, por natureza, universal, pensado como anterior ou alheia às próprias experiências históricas.
} 


\section{Referências}

ADAM, James (Ed.). The Republic of Plato. Cambridge: Cambridge University Press, 1902. Disponível em: <http://www.perseus.tufts.edu/hopper/text?doc=Perseus:text:1999.01.0167>.

Acesso em: 11 jan. 2019.

ANNAS, J. Doing without objective values: ancient and modern strategies. In: SCHOFIELD, M.; STRIKER, G. (Ed.). The Norms of Nature: Studies in Hellenistic ethics. Cambridge: Cambridge University Press, 2007. p. 3-29. Reimpressão da $1^{\text {a }}$ ed. de 1996.

ANNAS, J; BARNES, J. The modes of Scepticism. Cambridge: Cambridge University Press, 1997. Reimpressão da $1^{\mathrm{a}}$ ed. de 1985.

ARISTOTLE. On the Soul, Parva Naturalia, On Breath. With an English translation by W. S. Hett. Cambridge, MA: Harvard University Press, 2000. 1 a ed. de 1936.

BOLZANI FILHO, Roberto. Ceticismo e empirismo. Discurso, São Paulo, v. 18, p. 37-67, 1990.

BURNET, Ioannes. Platonis Opera. Oxford: Oxford University Press, 1973. t. 1. $1^{\mathrm{a}}$ ed. de 1900.

CICERO. On the Nature of the Gods, Academics. With an English translation by H. Rackham. Cambridge, MA: Harvard University Press, 1951. $1^{\text {a }}$ ed. de 1933.

EPICTETUS. The Discourses as reported by Arrian, The Manual and Fragments. With an English translation by W. A. Oldfather. Cambridge, MA: Cambridge University Press, 1956. v. 1.

FREDE, Michael. The Ancient Empiricists. In: Essays in Ancient Philosophy. Minneapolis: University of Minnesota Press, 1987. p. 243-260.

HUME, David. Investigação sobre o entendimento humano. Tradução de Leonel Vallandro. In: OS PENSADORES. São Paulo: Abril Cultural, 1973. v. 23. p. 127198.

PEREIRA, Oswaldo Porchat. Rumo ao ceticismo. São Paulo: UNESP, 2007.

SELLARS, John. The Art of Living: The Stoics on the Nature and Function of Philosophy. 2nd ed. London: Bloomsbury, 2009.

SEXTUS EMPIRICUS. Against Logicians. With an English translation by R. G. Bury. Cambridge, MA: Harvard University Press, 2006. First published in 1935.

SEXTUS EMPIRICUS. Agains Physicists, Against Ethicists. With an English translation by R. G. Bury. Cambridge, MA: Harvard University Press, 2006. First published in 1936.

SEXTUS EMPIRICUS. Against Professors. With an English translation by R. G. Bury. Cambridge, MA: Harvard University Press, 1949.

SEXTUS EMPIRICUS. Outlines of Pyrrhonism. With an English translation by R. G. Bury. Cambridge, MA: Harvard University Press, 1933.

SPINELLI, Emidio. Beyond the Theoretikos Bios: Philosophy and Praxis in Sextus Empiricus. In: BÉNATOUÏL, Thomas; BONAZZI, Mauro (Ed.). Theoria, Praxis and the Contemplative Life after Plato and Aristotle. Leiden: Brill, 2012. p. 101-117.

Autor(a) para correspondência: Alice Bitencourt Haddad, Universidade Federal Fluminense, Rua Professor Marcos Waldemar de Freitas Reis, São Domingos, 24210201, Niterói - RJ, Brasil. alicecorreio@gmail.com

HADDAD, Alice Bitencourt. A phýsis em Sexto Empírico e a concepção da natureza como guia para a vida. Griot : Revista de Filosofia, Amargosa - BA, v.19, n.1, p.254-265, fevereiro, 2019. 